\title{
Fold pattern analysis around Kanjamalai Salem district Tamilnadu
}

\author{
V. Thirukumaran ${ }^{\text {a, }}$, R. Suresh ${ }^{\text {b }}$ \\ "Department of Geology, Government Arts College (Autonomous), Salem - 636007, India. \\ ${ }^{\mathrm{b}}$ Department of Geology, Periyar University, Salem-636011, India \\ * Corresponding Author: geogacslm7@gmail.com
}

Received : $05^{\text {th }}$ July 2020, Accepted : $18^{\text {th }}$ October 2020

Abstract: Kanjamalai one of the fascinating location in Southern Granulite Terrain (SGT) for studying Archaean geology and structures as the entire hill is made up of variety of rock types like two pyroxene granulite, amphibolites, quartzo - feldsapthic gneisses, banded iron formation, and intrusive rocks like dunite, peridotite and pegmatite and beautifully carved structures. The entire hill resembles a canoe shape with doubly plunging fold structure with EW elongation. The entire hillock seems to sit pretty on mylonitised hornblende biotite gneisses which also have a common N70-95 degree trend and sub vertical dip with NE plunge which is in contradiction to centrally plunging lineations of the hill. The SW part of Kanjamalai near Chinasrirangapadi was displaying beautiful fold structures, with interference pattern out of which six domains were selected for detailed study and analysis. The multiple generation folded structure will have a clue in reconstructing the deformation history of this Kanjamalai. The observed f1, f2 and f3 folds show significant Type III interference pattern as that of Ramsay and 01 and 03 type folds of Bernhard Grasemann. Wavelength -amplitude analysis was made to generalize and regroup the observed folds in to high amplitude, high wavelength or open folds, low wavelength and Mesoscopic folds. And visual harmonic analysis was made to analyse the symmetry of the folds and analyze the geometry, symmetry and harmony and genesis of the fold in terms of relative timing of the events.

Keywords: Fold pattern, Fold interference, Polyharmonic folds, Parasitic folds.

\section{Introduction}

Fold pattern analysis will give a comprehensive picture on the geometry and harmony of the folds and in turn that reflects in the kinematics involved can be predicted. Folds are found over a wide range of scales and the people often need to express the size in an appropriate way. It may be convenient in general descriptions to give a picture in average 
metric terms. For more exact descriptions people need to apply the mathematical concepts of wavelength and amplitude and visual harmonic analysis.

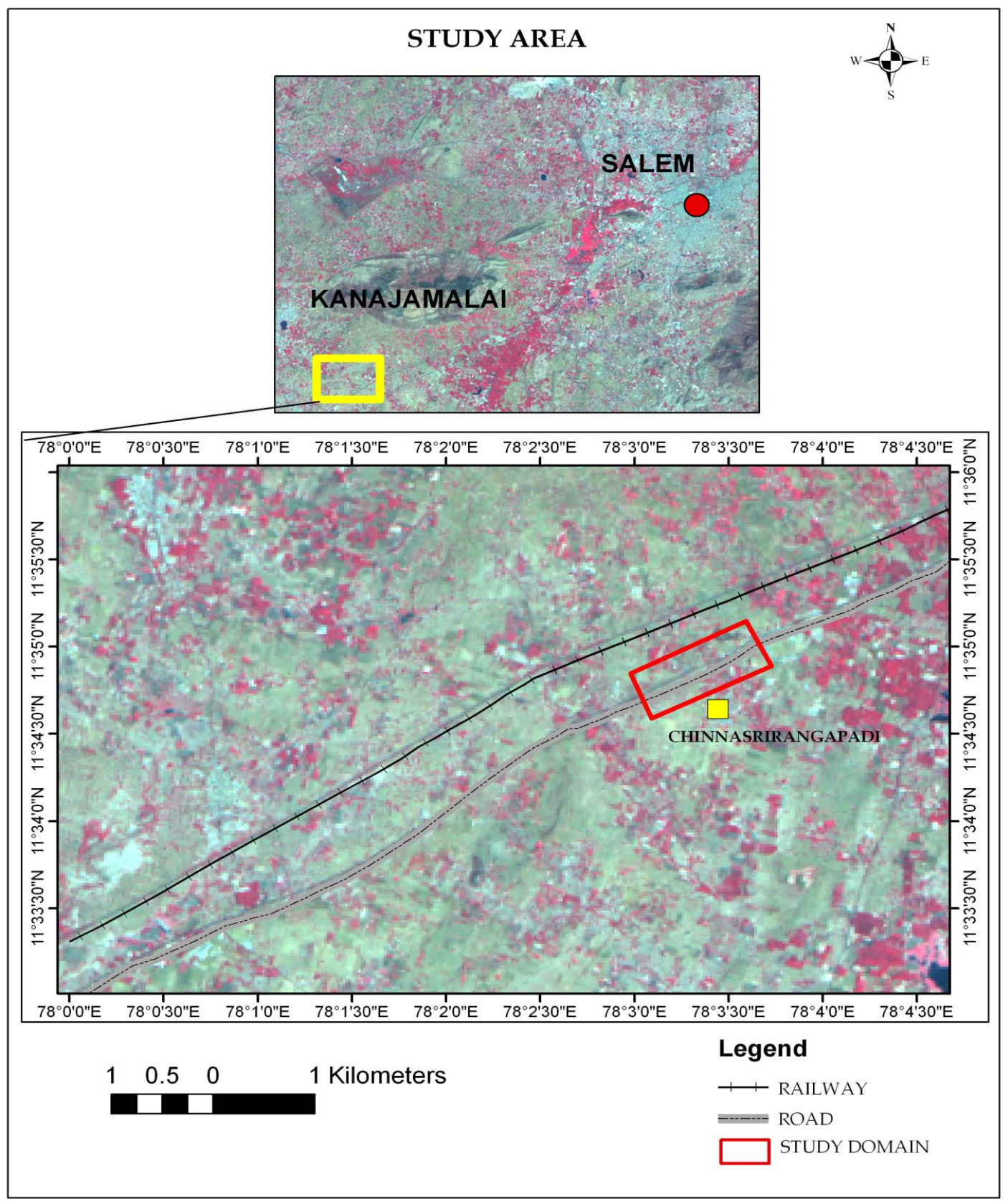

Figure 1. Study area 


\section{Wavelengths -Amplitude Analysis}

If folded rocks showed the regular geometry of simple sinusoidal waves there would be no problem in doing this, but natural folds do not show such symmetry or periodic regularity. Each fold domain must be analyzed separately, each fold having its own wavelength and amplitude. The general trend of the folded layer can be found by joining successive inflexion points, and this join defines the median surface of the folds. To determine the wavelength $\mathrm{W}$ of individual folds we measure the distance between the two inflexion lines defining the fold domain, and this distance is the half wavelength of the fold $W / 2$. For this domain construct a line parallel to the inflexion line join so as to touch the extremity of the fold. The distance between these lines is the fold amplitude $\mathrm{A}$.

When the median surface of a folded layer is constructed it may be found that this has a curving or folded form. The folded form of the median surface can be analyzed in the same way as was done for the original folds and in so doing larger characteristic wavelengths and amplitudes of the folded surface can be established. Fold wave trains with two or more orders of wavelengths and amplitudes are known as polyharmonic folds. The folds of smallest wavelength are sometimes called as parasitic folds on the larger wavelength structure. The term anticlinorium and synclinorium describe polyharmonic folds where the larger scale folds are antiformal and synformal respectively. In the present study area, six domains $\mathrm{A}$ to $\mathrm{F}$ were selected. The varying amplitude and wavelength were measured using the photograph of the domain. Since, the ratio of amplitudes and wavelength were taken there may not be any variation in the metric values (Figure 5). The values were measured and tabulated domain wise (Table 2). Scatter plot was constructed for half of the wavelength and amplitude using SPSS software. The scatter plot was regrouped based on the amplitude and wavelength values as

1) High amplitude folds

2) High wave length folds open folds

3) Low wavelength low amplitude folds

4) Mesoscopic folds

There was great correlation between the values (the geometry) and genesis of the fold. In order to establish this visual harmonics analysis was done.

The high amplitude folds were also called as explosive folds. The high amplitude folds were compared with $\mathrm{O}_{3}$ type fold of Bernhard Grasemann, et al.,(2004) where the previous fold was superimposed by another with same attitude (Figure 4) [1].

The high wavelength folds are also called as open fold and they were Oitype of Bernhard Grasemann, et al.,(op.cit.) where the previous folds was superimposed by another with horizontal axial plane possible represent a horizontal thrust (Figure 4) [1]. 


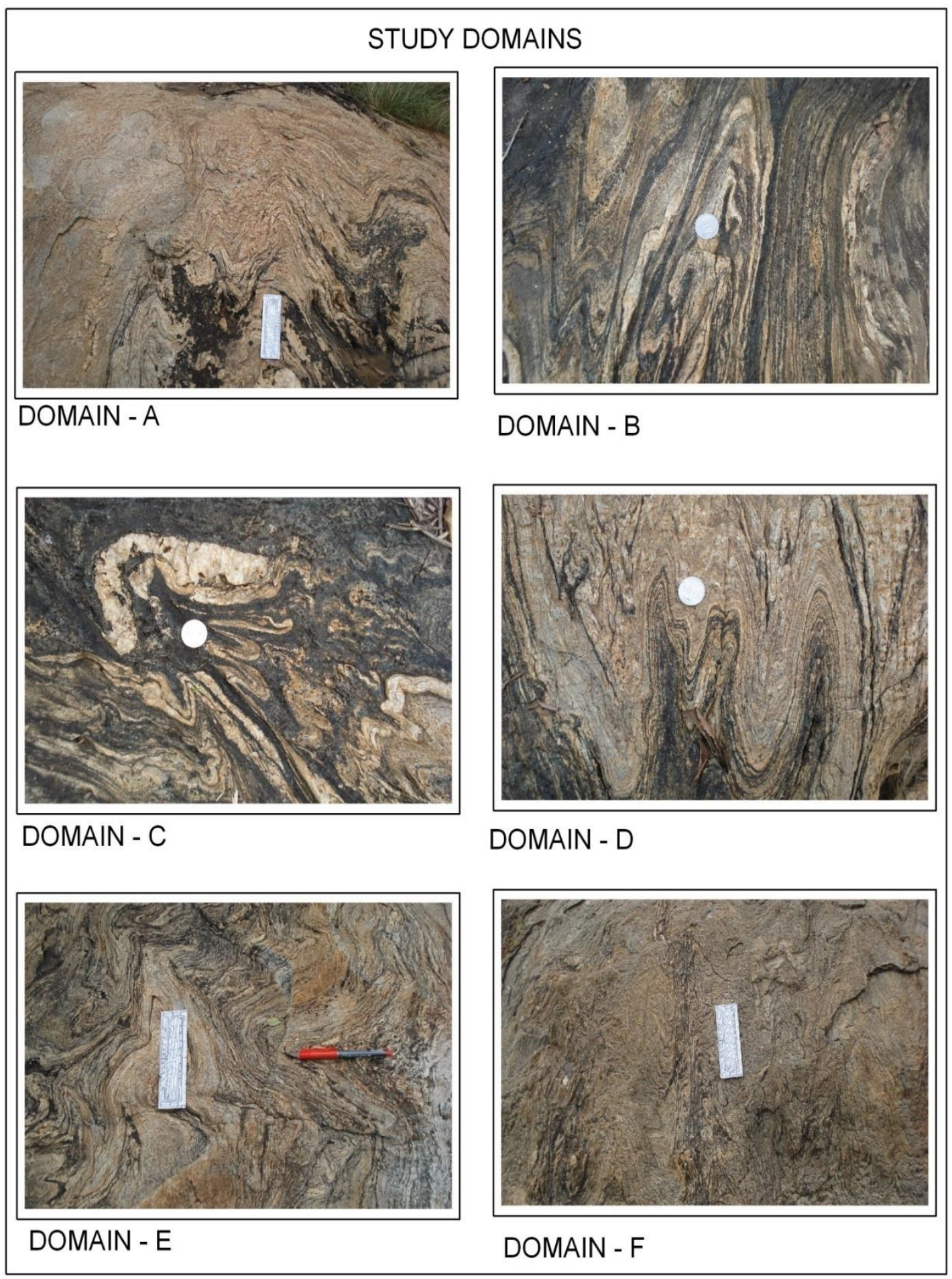

Figure 2. Six Domains of Study 
Table 2. Wavelengths - Amplitudes of folds in six domains

\begin{tabular}{|c|c|c|c|c|}
\hline DOMAIN & Fold No & Wavelength "W" & $\mathrm{W} / 2$ & Amplitude “ A" \\
\hline \multirow[t]{4}{*}{ A } & 1 & 4.2 & 2.1 & 4.7 \\
\hline & 2 & 2.5 & 1.25 & 3 \\
\hline & 3 & 2 & 1 & 2.3 \\
\hline & 4 & 3.5 & 1.85 & 3.9 \\
\hline \multirow[t]{4}{*}{ B } & 5 & 4.2 & 2.1 & 6 \\
\hline & 6 & 2 & 1 & 4.5 \\
\hline & 7 & 2.3 & 1.15 & 4 \\
\hline & 8 & 2.2 & 1.1 & 4.5 \\
\hline \multirow[t]{6}{*}{$\mathrm{C}$} & 9 & 1.4 & 0.7 & 1.5 \\
\hline & 10 & 1.4 & 0.7 & 1.6 \\
\hline & 11 & 1.6 & 0.8 & 1.9 \\
\hline & 12 & 2.1 & 1.05 & 1.4 \\
\hline & 13 & 1.6 & 0.8 & 1.5 \\
\hline & 14 & 1.5 & 0.75 & 1.7 \\
\hline \multirow[t]{5}{*}{$\mathrm{D}$} & 15 & 2.5 & 1.25 & 4.5 \\
\hline & 16 & 2.2 & 1.1 & 4.9 \\
\hline & 17 & 3.2 & 1.6 & 3.4 \\
\hline & 18 & 5 & 2.5 & 4.2 \\
\hline & 19 & 3.4 & 1.7 & 4.6 \\
\hline \multirow[t]{7}{*}{$\mathrm{E}$} & 20 & 3.9 & 1.95 & 2 \\
\hline & 21 & 1 & 0.5 & 1 \\
\hline & 22 & 4 & 2 & 4.7 \\
\hline & 23 & 3.7 & 2.35 & 5.6 \\
\hline & 24 & 2.4 & 1.2 & 3.3 \\
\hline & 25 & 2.5 & 1.25 & 2.7 \\
\hline & 26 & 3 & 1.5 & 2.2 \\
\hline \multirow[t]{12}{*}{$\mathrm{F}$} & 27 & 0.6 & 0.3 & 1 \\
\hline & 28 & 0.9 & 0.5 & 1 \\
\hline & 29 & 1.9 & 1.2 & 1.5 \\
\hline & 30 & 0.9 & 0.45 & 1.6 \\
\hline & 31 & 1.4 & 0.7 & 1 \\
\hline & 32 & 0.5 & 0.25 & 0.9 \\
\hline & 33 & 0.8 & 0.4 & 0.6 \\
\hline & 34 & 1 & 0.5 & 0.5 \\
\hline & 35 & 0.8 & 0.4 & 0.8 \\
\hline & 36 & 1.8 & 0.9 & 2.2 \\
\hline & 37 & 1.2 & 0.6 & 0.8 \\
\hline & 38 & 0.6 & 0.3 & 0.7 \\
\hline
\end{tabular}


Low wavelength low amplitude folds were parasitic in nature and which form around the major folds.

The Mesoscopic scale folds are general $\mathbf{F}_{2}$ folds which show a striking bending of $\mathbf{S}_{1}$ planes. The $\mathrm{f1}$ folds were forming tight rootless folds and were parallel to S1 planes and they bend to form $\mathrm{f} 2$ folds.

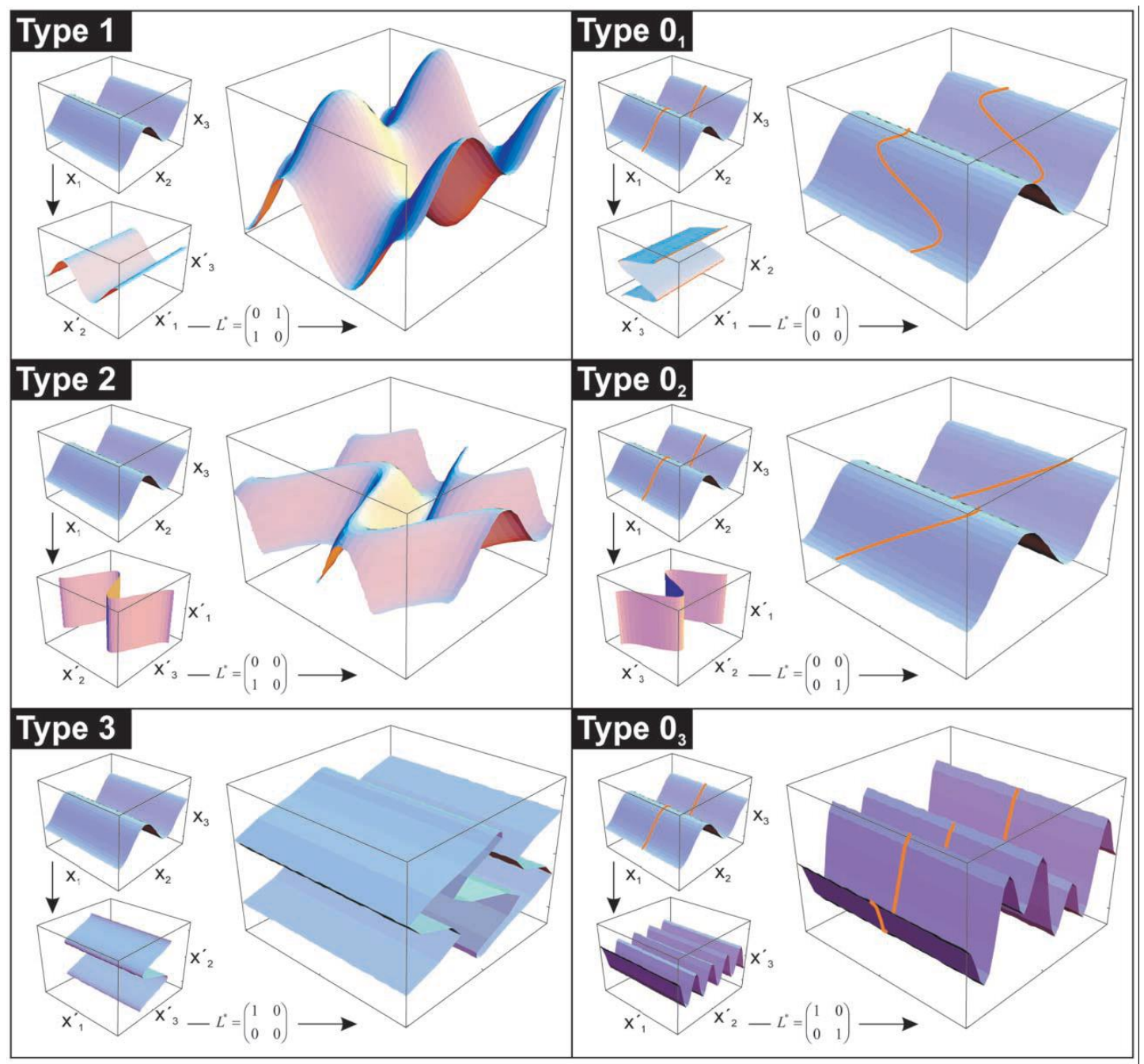

Figure 3. Three-dimensional geometry of the six end - member refold structures. Marker lines on type $0_{1}-0_{3}$ refolds clearly reveal the different finite deformation recorded by the structures. In order to highlight the geometry of type $0_{3}$ refolds, the superposed fold has a three times shorter wavelength responsible for the second-order folds of the finite structure. The kinematic models were calculated using the software Mathematica (Wolfram 1999) and the package Fold Plot (Moore and Johnson 2001). 


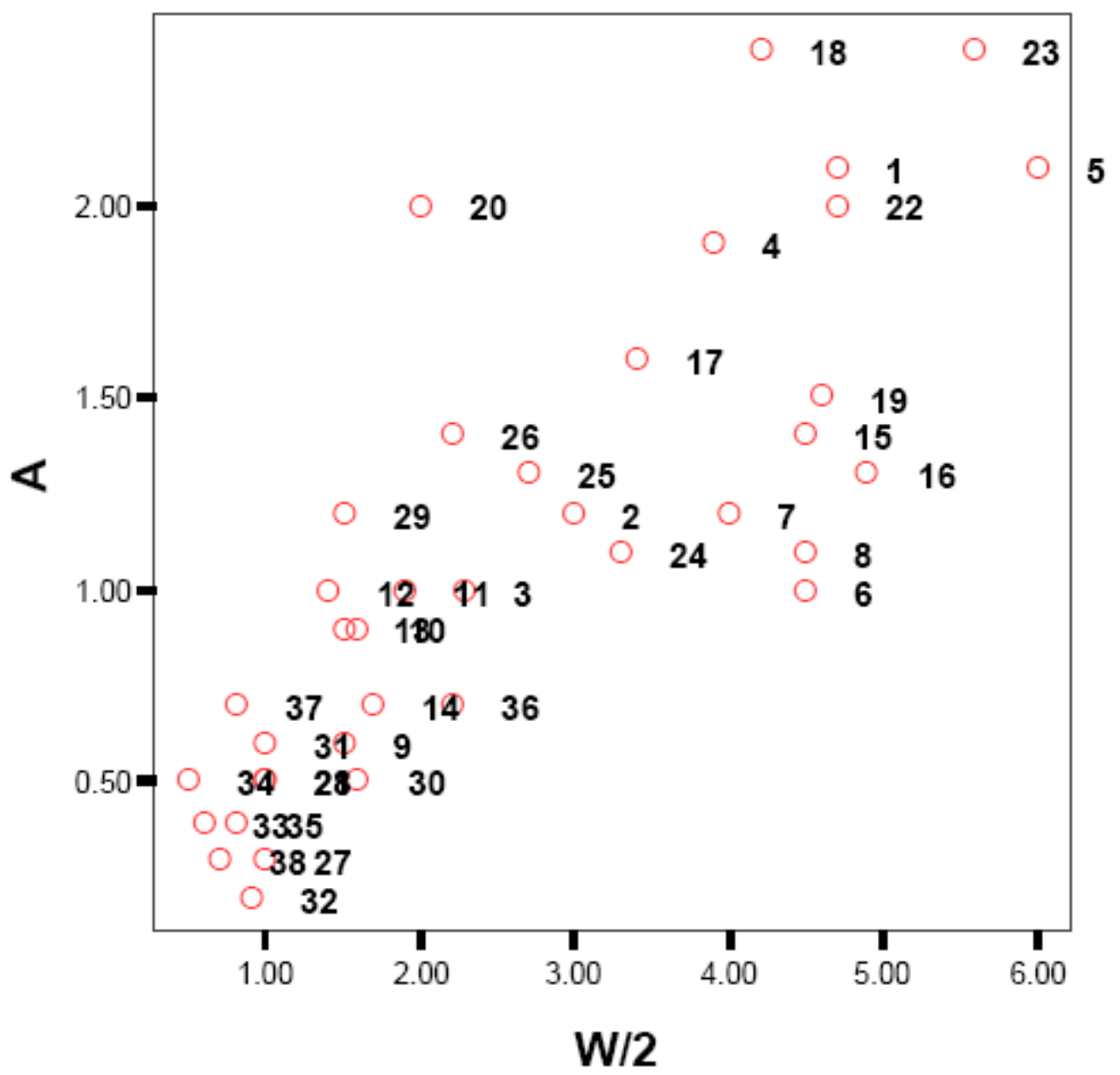

Figure 4. Wavelength -Amplitude scatter plot and classification of folds

\section{Visual Harmonic Analysis / Fourier Analysis}

Several new definitions to describe fold geometry have to be introduced when people consider the relationships of adjacent folded surfaces. The inflexion lines on successive surface can be joined up to form surface known as inflexion line surfaces, and these completely define the various fold domains in three dimensions. An inflexion surface may end at some line in rock. This implies that a fold in one layer becomes of progressively smaller amplitude in adjacent layers and that this amplitude continues to decrease until a point where the layer are unaffected by folds. In other instances adjacent inflexion surfaces converge to produce lensshaped region in three dimensions, and these "pods" completely delimit a particular fold domain.

An visual analysis was made on six domains to analyze the geometry, symmetry and harmony and genesis of the fold in terms of relative timing of the events. 


\section{Domain A}

The domain A was showing abroad open folds with wavy thin felsic bands containing boudins of $\mathrm{F} 1$ folds. This wavy band represent $\mathrm{O} 1$ type interference pattern which is due to the superposition of recumbent shear folds on upright folds with fold axes parallel to the shear direction probably forming type $\mathrm{O} 1$ refold structures may most likely have a close kinematic relationship in large detachment zones (Mancktelow and Pavlis 1994) (Figure 5) [2].

\section{Domain B}

A superb example of a natural type 02 refold from the Singhbhum shear zone (India), including a physical model of an intermediate type $2 \leftrightarrow 02$ structure, has been published recently by Sengupta and Koyi (2001) [3]. The experiments produced by Grujic and Mancktelow (1995) are comparable to the kinematic axes of type 02 refolds. Furthermore, it is generally accepted that, in shear zones, passive, highly noncylindrical folds may develop by amplifications of deflections eventually forming sheath folds (e.g., Cobbold and Quinquis 1980) [4,5]. Progressive shear deformation of such sheath folds could develop type 02 along both limbs and type 03 refold structures at the nose.

The domain B classically exemplifies the sheath folds at the limbs and amplifications of nose was well deserved to define as O3 type pattern (Figure 6)

\section{Domain C}

Considering incremental superposition of deformation, type O3 structures are probably the most common refold structures in nature, which permanently form during amplification of folds [6]. Considering that individual fold sets are uniform neither in scale nor orientation and that variable strain may result in both fold hinges and axial planes undergoing significant rotations, type O1-O3 refold structures are likely to form during progressive development of flow perturbation folds (Alsop and Holdsworth 2002) [7].

The Domain C exhibiting O3 interference pattern and development of S2 planes was very evidently supporting an event much latter to f2 folding and which has amplified the folds. The amplitude variations were due to the compositional variations with alternate felsic and mafic banding which has opened up the hinges and they were filled quartz pods (Figure 7).

\section{Domain D}

Surfaces which connect the hinge lines on adjacent layers are hinge line surfaces, more usually called axial surfaces or, when planar, axial planes. A fold domain may show one or more axial surfaces. Folds with converging paired axial surfaces are generally termed conjugate fold. Conjugate folds with rounded hinge zones are generally known as box folds, whereas those with sharp hinges are generally called conjugate kink fold. The axial surfaces of conjugate folds generally meet along a line somewhere in the structure. Beyond this line the fold may show only a single axial surfaces or the axial surfaces may cross one another, with one surface 
being displaced across the other. Rarely one finds fold domains with more than two axial surfaces; these are known as polyclinal flods. This domain exhibit polyclinal polyharmonic folds with the F2 fold axis amplified by F3 which also bends the quartz pods (Figure 8).

The axial surfaces of single hinge folds may come to a stop in a similar way to that described with inflexion surfaces, or they may form closed pod-like forms which isolate a limb region between two adjacent fold domains.

\section{Domain $\mathrm{E}$}

The domain D displays wonderful Type 3 interference pattern this type of fold morphology arises where the differential movement direction, A2, of the second phase lies at a high angle to the first fold axial planes, like that of Type 2 described already. It differs in that the B2 direction lies very close to the first fold hinge lines F2. This relationship means that although the first fold axial surfaces become curved, the first fold hinges are not markedly deflected. The three dimensional model of the purest form of this pattern is exactly that investigated in our card deck model. All the fold axial directions, both first and second phase, tend to be sub-parallel. This relationship implies that in most two-dimensional sections the first fold hinges will be unlikely to pass into and out of the section plane and that layer trace forms of closed type will not occur. The limbs of first folds which originally converged together or diverged away from the first fold axial surfaces will therefore continue to do so even after refolding.

The domain $\mathrm{E}$ shows type 3 interference patterns and the $\mathrm{F} 2$ axis was folded by the F3 folding where the F1 folds forms tight rootless folds within S1 planes. The F3 fold axis shows a conjugate pattern and this type of interference is unique in Domain E. the axis orients $85-105$ degrees and representing E-W compression (Figure 9).

\section{Domain $\mathrm{F}$}

The position of axial surfaces of a fold on the ground surfaces is known as the fold axial race. If a hinge line is horizontal, the strike of the axial trace is parallel to the trend of the hinge line, but if the axial surfaces is inclined and the fold hinge has a definite angle of plunge the axial trace and axial trend will not be parallel

If the median surface of a fold and the axial surface are perpendicular and if, the axial surface divides the fold domain into mirror symmetric quarter waves, and then the fold is termed symmetric. If either of these conditions is not met, the fold is asymmetric. The relationships of the symmetry of parasitic folds in polyharmonic fold are very systematic: the limbs of the larger wavelength structure show asymmetric parasitic folds, whereas the hinge zone shows symmetric parasitic folds. Where the folds have inclined hinge lines the differing symmetry forms of the parasitic folds can be indicated by designating their shapes with symbols, $\mathrm{M}$ for symmetric folds, $\mathbf{S}$ or $\mathbf{Z}$ for asymmetric folds. These symbols express the fold shape as it would appear on a horizontal surface. The relationships of these forms to position 
in the major structure and the methods for recording the symbols on a map should be clear. The interpretation of these symbols on a map can be an extremely valuable tool for deciphering large scale fold geometry.
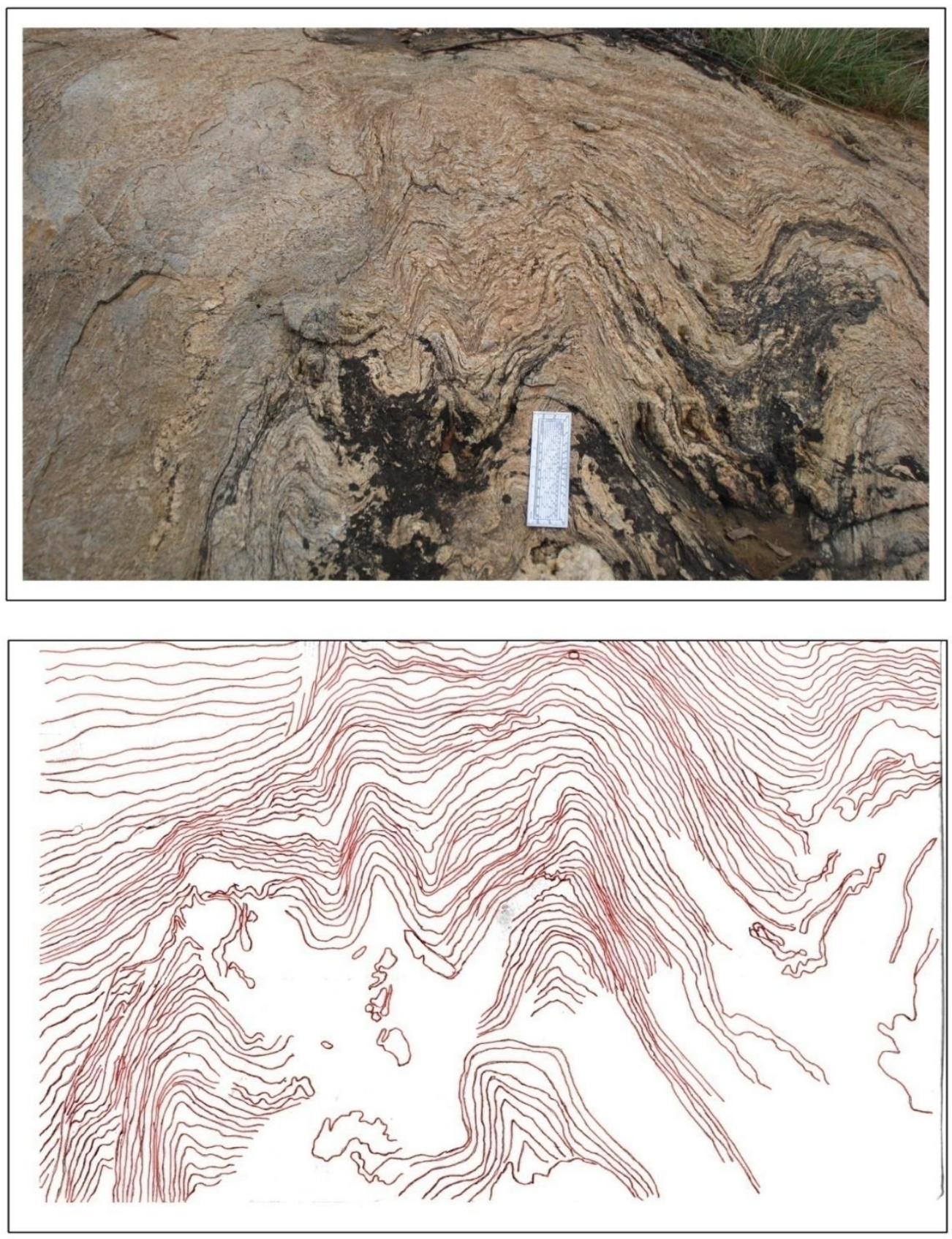

Figure 5. Type OA Interference Pattern in Domain A 

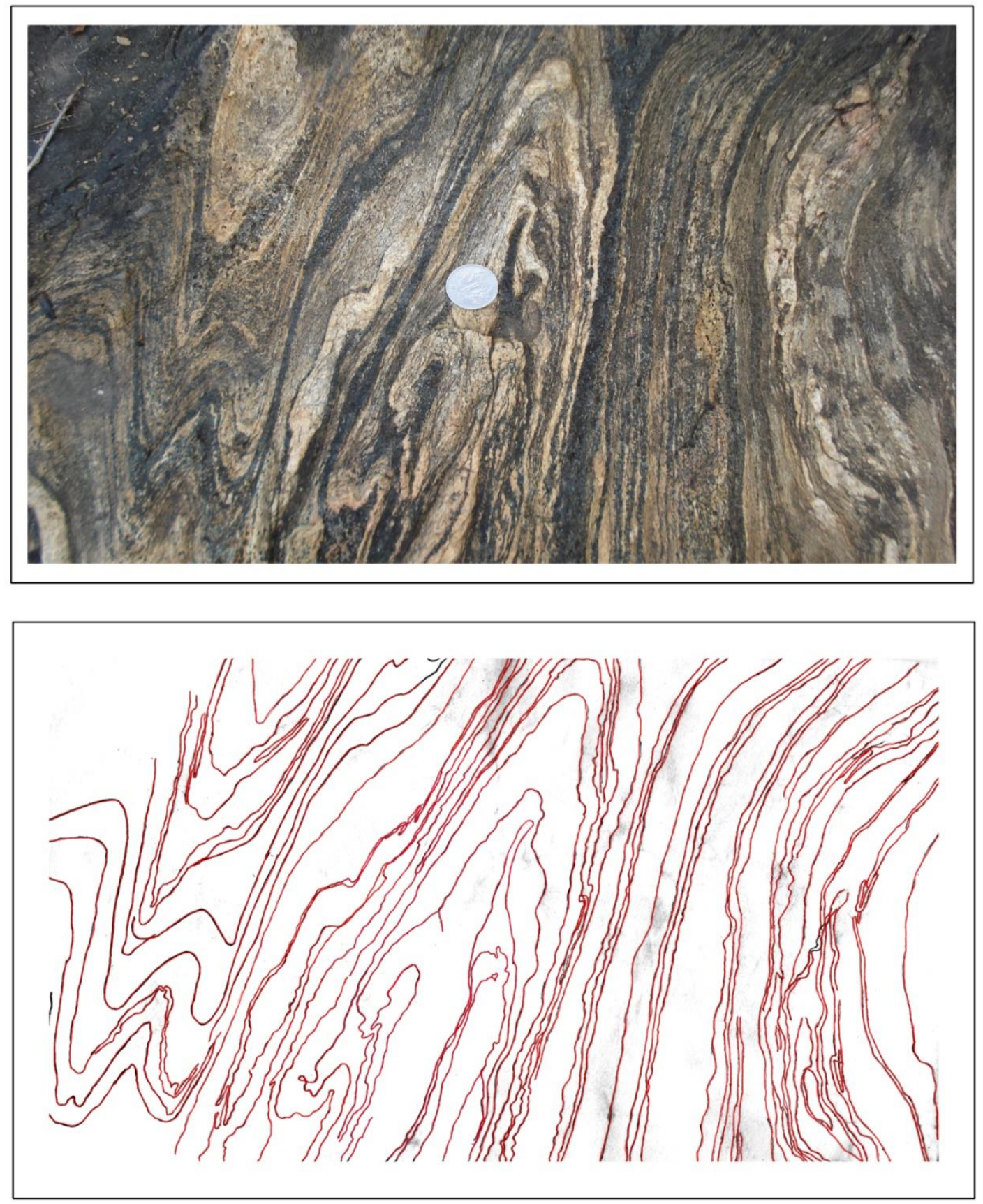

Figure 6. Sheath Fold, Polyclinal and Explosive Polyharmonic folds

Where the fold hinge lines are horizontal these symbols cannot be used to indicate fold symmetry on a map, and some other methods of describing the relationships of the axial surfaces of the parasitic folds to the median lines of the folded layers must be employed. 
The sinistral pattern was observed along the 95 degree vertically dipping shear planes. The folds were the result of dragging along the shear plane and such a shear planes were suggestive of the kinematics involved (Figure 10).
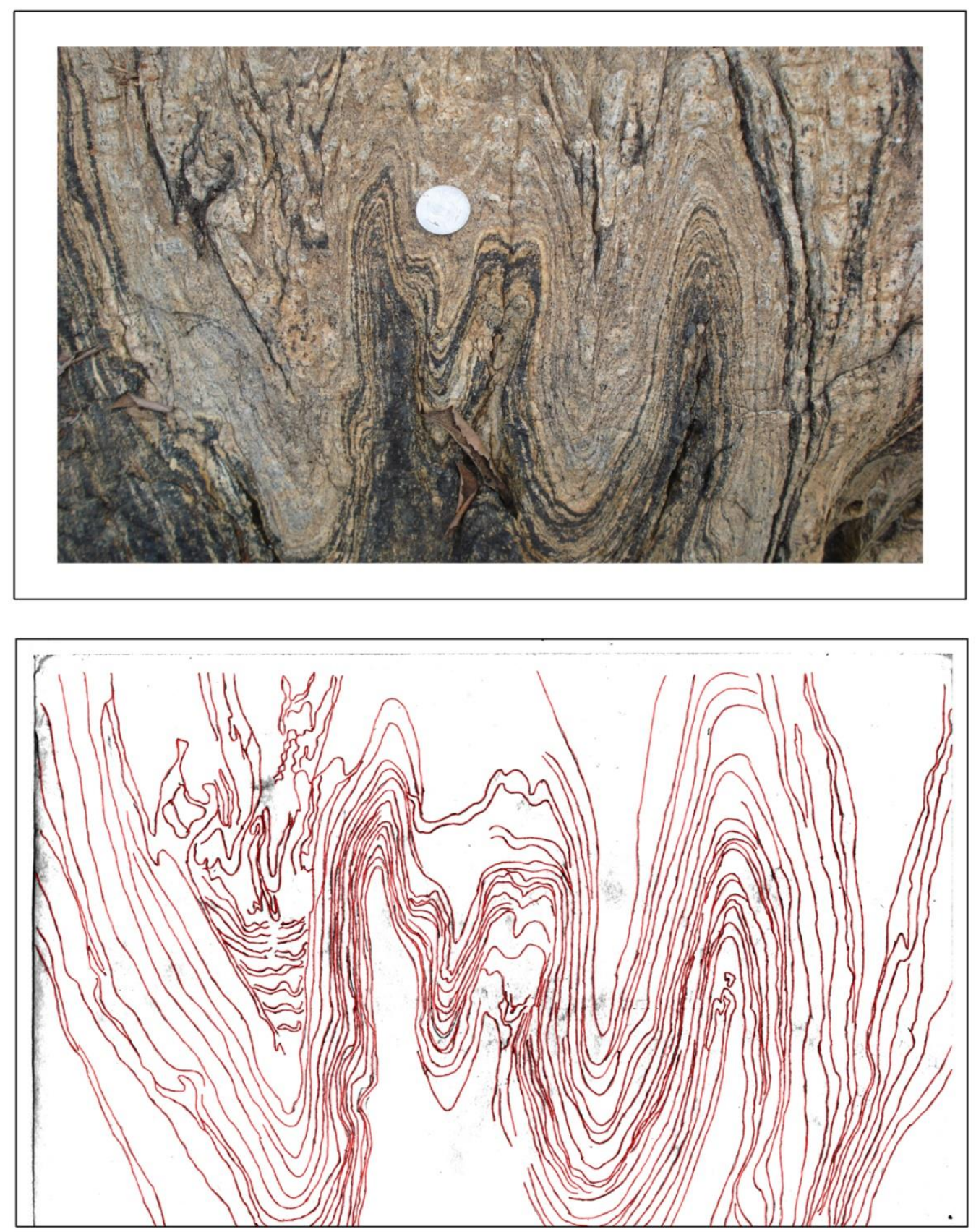

Figure 7. S2 planes parallel to fold axis and Polyclinal Polyharmonic folds 

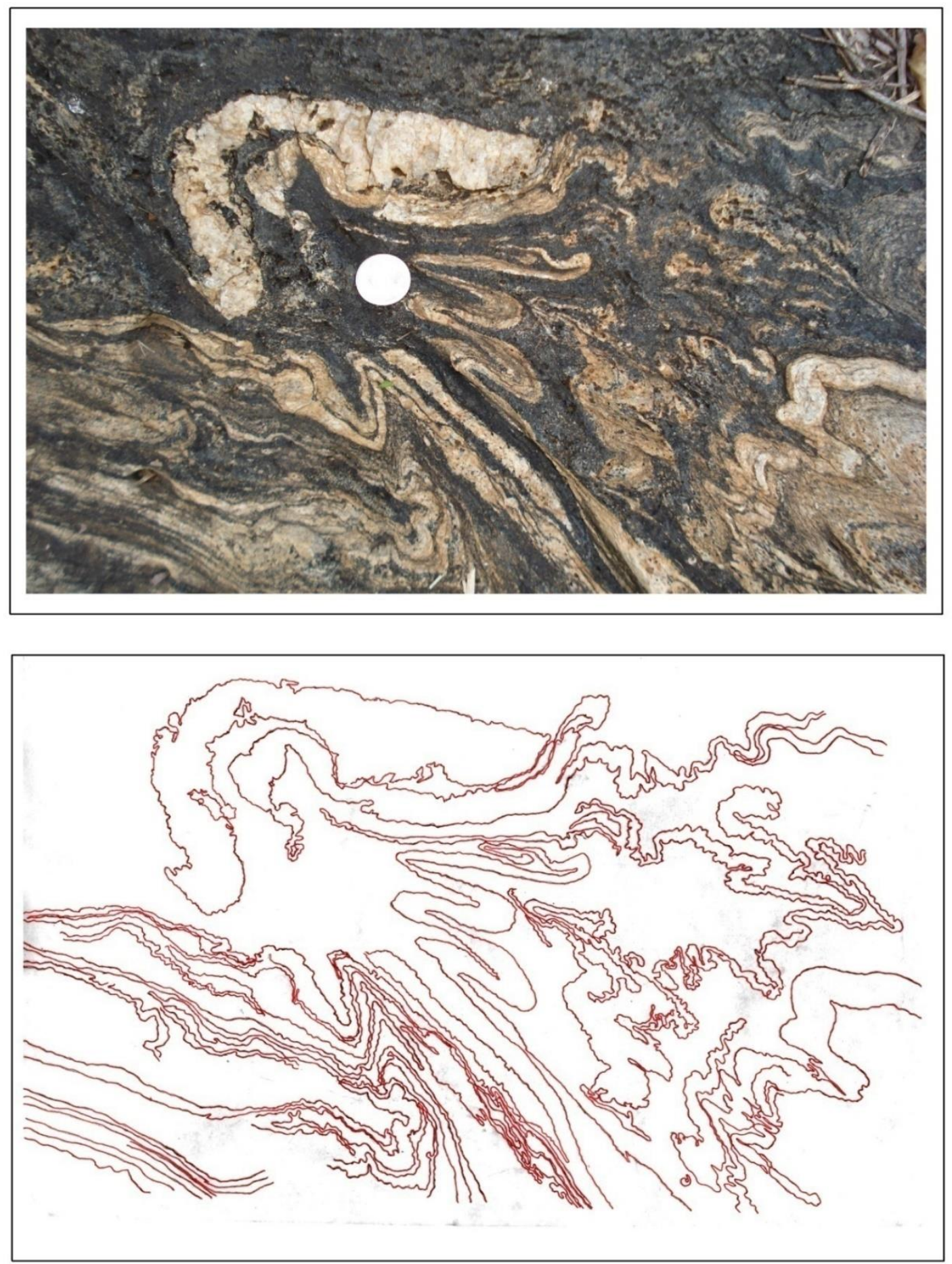

Figure 8. F3 Folding and Polyharmonic Folding along Felsic and Mafic Components 

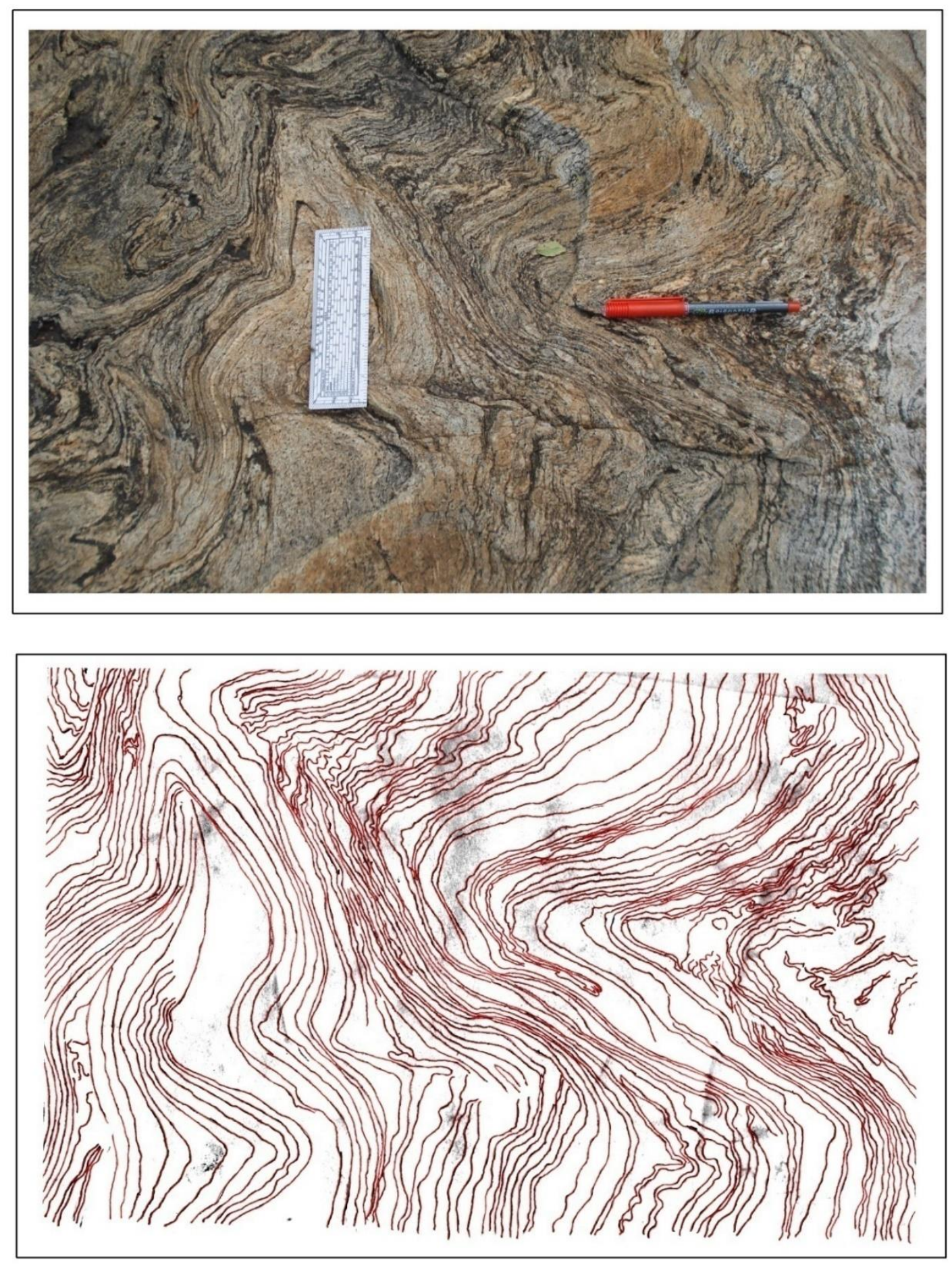

Figure 9. Type 3 interference pattern with Conjugate F3 fold axes 

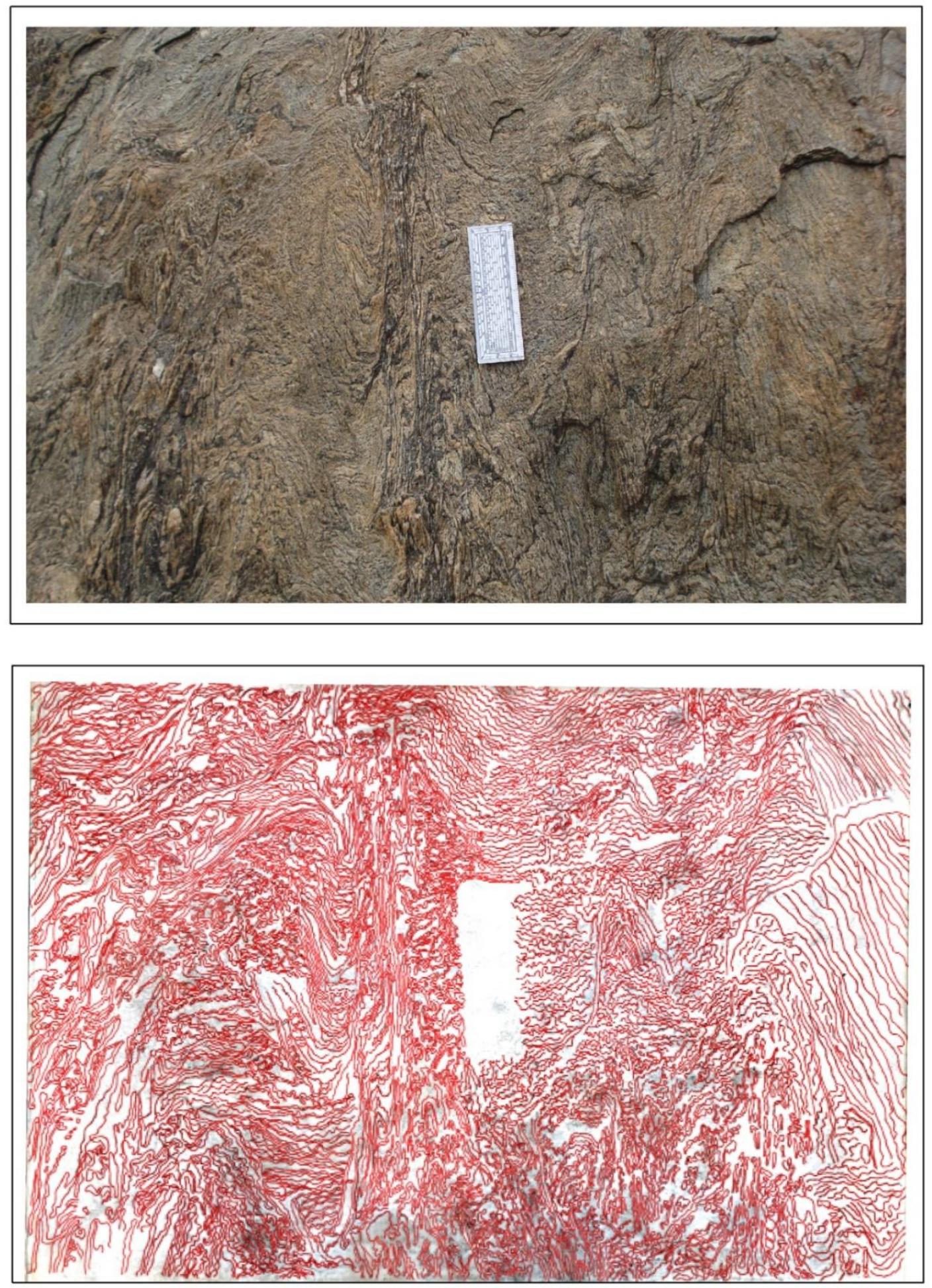

Figure 10. Sinistral Shear Bands in Domain F 


\section{TECTONIC IMPLICATIONS}

The Kanjamalai is known for its doubly plunging structure and yet a solid theory is needed to substantiate it as the very location of the hill within mylonitised zone would suggest a different idea to find.

The mylonitised zone was extensive on either side of Kanjamalai as thick as few kilometers as shown in lithology map (Figure 2). But the concentration of folded layers are restricted to certain zones probably only within the study window taken. This mylonitised zone was representation of proterozoic Moyar-Bhavani shear zone. Everywhere the rocks exhibit dextral sense of shear. The Moyar shear zone (MSZ) may be a terrain boundary along which the Archaean dharwar craton and the late Archaean Nilgiri block were amalgamated - $2.5 \mathrm{Ga}$ age [8]. The Moyar and Bhavani shear zones (MSZ and BSZ) are dextral shear zones in contrast to their being up thrust $[9,10]$. Westward rotation of regional Dharwar trends along MSZ is due to folding.

The Extension of the BSZ/MSZ into the Eastern Ghat mobile belt (EGMB) in contrast to the truncation of two shears, namely the Nallamalai shear and the Cuddapah eastern margin shear against the MSZ and PCSZ, respectively (GSI \& ISRO, 1994) [9]. The BSZ is a dextral shear zone [9]. BSZ is dextral as well as sinistral (Meissneret al. 2002) [11].

The Gradual rotation of the regional trends on either side of the MSZ reveals its dextral shear character having large strike-slip component in contrast to the earlier observations by Naha and Srinivasan (1996), who postulated large-scale up thrust displacements. In the western parts, the Moyar River flows along this zone, this is then occupied by the eastwardflowing Bhavani River around Satyamangalam [10]. The shear zone skirts the northern margin of Sankaridurg and extends uninterruptedly eastwards towards Salem and Attur [12-15]. The MSZ is characterized by strong penetrative mylonitic shear foliation, which trends almost E-W in the western parts and dips very steeply both towards the north as well as south. A subordinate trend of foliation having $\mathrm{N} 30^{\circ} \mathrm{E}$ orientations also noteworthy and may correspond to the relict N-S foliation of the Northern massifs within the shear zone. Numerous shear criteria like asymmetric mafic boudins within the MSZ reveal distinct ductile dextral shear sense of movement, with mylonitic foliation characterized by sub horizontal to gently plunging mineral/stretching lineation. However, the mylonitic foliation also contains variable sub vertical to steeply down-dip plunging lineations towards NW or SE as well as towards west. Further, the gradual rotation of axial surfaces of tight to isoclinals folds due to dextral shearing within the MSZ. The main orientation of the ductile shear zones within the MSZ is almost E-W, having both north/ south dips and a minor component of NE trending sinistral shear zones. Further eastwards in the Satyamangalam region, orientation of dextral shear zones has slightly changed to $\mathrm{S} 80^{\circ} \mathrm{E}$ with steep northerly dips while sinistral shears remain oriented at $\mathrm{N} 30^{\circ} \mathrm{E}$ with steep $\mathrm{E} / \mathrm{W}$ dips. In the easternmost region of Attur, where both the conjugate sets are well developed, dextral shear zones trend S $70 \mathrm{E}$ with very steep to vertical dips and the sinistral 
ductile shear zones are oriented $\mathrm{N} 20^{\circ} \mathrm{E}$. All along the MSZ, mineral/stretching lineations are well developed on the mylonite foliation and within ductile shear zones, and plunge either steeply down-dip or undergo rotation to become moderate to gentle [10, 14, 15].

The intersection of Tiruchengode shear zone corresponds and syntectonic to Sankagiri granite emplacement. The mylonite bands reported by Thirukumaran and Saravanan (2010) near amphibolite area in Tiruchengode with N-S orientation have had a ramp structure due to intrusion thrusting of Sankagiri granite [16]. The mylonite bands do have a dextral sense of shearing and they intersect the Moyar -Bhavani shear near the study window. This was an amazing part of tectonics which brought out another episode of deformation to already deformed Moyar -Bhavani shear.

The identification of fold interference patterns in the field provides significant insight into the shortening history and kinematic controls of deformation within studied terranes. The geometry of superimposed fold generations to produce fold interference patterns is well understood (e.g. Ramsay, 1962; Thiessen and Means, 1980; Ramsay and Huber) However, not all rocks deform in an ideal manner to produce 'classic' fold interference patterns, and map and outcrop patterns of fold interference patterns can easily become complex, as demonstrated by Thiessen (1986) $[6,17,18]$. Cross-sections through a fold interference pattern that result in the perfect representation of a Type 2 or Type 3 outcrop pattern are not always preserved. Thiessen (1986) showed that parallel cross-sections through refolded folds can produce a wide variety of patterns. Fold interference patterns that appear highly complex in outcrop can be described using simple refolding geometries, and vice versa; patterns that appear simple may be attributed to more complex refold histories [18]. Therefore, it is important to attempt to observe the complete structure of an area and not make conclusions from observation of any one part of a structure.

Six domains were selected and analysis was made on wavelength and amplitude and the analysis suggested different types of fold like and the analysis of the six domains. The F1 folds were occurring as tight rootless folds and there is no significant orientation could be read from that and F2 folding has general orientation of 55 to 65 degree but lack their attitude where they were folded again.

The F3 folding episode has perpetrated the original structure and their orientation is 85 to 105 degrees. Type 3 interference pattern was observed in domain $\mathbf{E}$ but at the same time type $\mathrm{O} 1$ and $\mathrm{O} 3$ type were also found. Such polyharmonic interference pattern could be related to

1) Radial thrust pattern from Sankagiri pluton

2) Superimposition of single system of folding over earlier folded and subverging mylonite. This was very clear by the variously oriented F2 folds and also with steeply plunging $\mathrm{F} 2$ folds on the north eastern side. 


\section{CONCLUSION}

In the present study area, six domains $\mathrm{A}$ to $\mathrm{F}$ were selected. The varying amplitude and wavelength were measured using the photograph of the domain. Based on the wavelength analysis following types of folds were identified.

1) High amplitude folds

2) High wave length folds open folds

3) Low wavelength low amplitude folds

4) Mesoscopic folds

Their geometry was visually analyzed and harmony was studied and interpreted in the form of their genesis.

Different types of interference pattern were identified and some of the newest interference pattern was identified in the study area. The type 3 interference pattern and type $\mathrm{O} 1$ and $\mathrm{O} 3$ were significantly conveys two different theories that the complex polyharmony was attributed to radial N, NE and NNE thrust owing to emplacement of Sankagiri pluton and superimposition of last phase of deformation over easterly subverging mylonitic folds of earlier origin.

\section{References}

[1] B. Grasemann, G. Wiesmayr, E. Draganits, F. Fusseis, Classification of refold structures, The Journal of geology, 112 (2004) 119-125.

[2] N.S. Mancktelow, T.L. Pavlis, Fold-fault relationship in low-angle detachment systems, Tectonics, 13(1994) 668-685.

[3] S. Sengupta, H.A. Koyi, Modifications of early lineations during later folding in simple shear. In H.A. Koyi, and N.S. Mancktelow, eds. Tectonics modeling: a volume in the honor of Hans Ramberg. Oulder, colo., Memoirs - Geological Society of America, 193(2001) 51-68.

[4] D. Grujic, N.S. Mancktelow, Folds with axes parallel to the extension direction: an experimental study, Journal of Structural Geology, 17 (1995) 279-291.

[5] P.R. Cobbold, H. Quinquis, Development of sheath folds in shear regimes, Journal of structural geology, 2 (1980) 119-126.

[6] R.L. Thiessen, W.D. Means, Classification of fold interference patterns: a re-examination. Journal of Structural Geology, 2(1980) 311-326.

[7] G.I. Alsop, R.E. Holdsworth, The geometry and kinematics of flow perturbation folds, Tectonophysics, 350 (2002) 99-125. 
[8] M.M. Raith, C. Srikantappa, D. Buhl, H. Kohler, The Nilgiri enderbites, south India: nature and age constraints on protolith formation, high-grade metamorphism and cooling history, Precambrian Research, 98(1999) 129-150.

[9] S.A. Drury, N.B. Harris, R.W. Holt, G.J. Reeves-Smith, R.T. Wightman, Precambrian tectonics and crustal evolution in South India, The Journal of Geology, 92(1984) 3-20.

[10]K. Naha, R. Srinivasan, Nature of Moyar and Bhavani Shear Zones, With a note on its implication on the tectonics of the Southern India Precambrian shields, Proceedings of the Indian Academy of Sciences - Earth and Planetary Sciences, 105(1996) 173-189.

[11]B. Meissneret, P. Deters, C. Srikantappa, H. Kohler, Geochronological evolution of the Moyar, Bhavani and Palghat shear zone of Southern India: implications for eastern Gondwana correlations, Precambrian Research, 114(2002) 149-175.

[12]V. Srinivasan, Geological structures in Attur valley, Tamil Nadu, based on photointerpretation, Journal of the Geological Society of India, 15(1974) 89-92.

[13]T.R.K. Chetty, Proterozoic shear zones in southern granulite terrain, India, The Archaean and Proterozoic Terrains in Southern India within East Gondwana, 3 (1996) 77-89.

[14]T.R.K. Chetty, Y.B. Rao, Behaviour of stretching lineations in the Salem-Attur shear belt, southern granulite terrane, South India, Journal of the Geological Society of India, 52 (1998) 443-448.

[15]B.K. Bhadra, Ductile shearing in Attur shear zone and its relation with Moyar shear zone, South India, Gondwana Research, 3 (2000) 361-369.

[16] V. Thirukumaran, and Saravanan, (2010) Study on Nappe structure near Tiruchengode, an unpublished M.sc. dissertation report. Dept. of geology, government arts college (Autonomous) Salem-7.

[17]J.G. Ramsay, R.J. Lisle, The techniques of modern structural geology. Volume 3, Application of continuum mechanics in structural geology. London, Academic Press, 3 (2000) 701-1061.

[18]R.L. Thiessen, Two-dimensional refold patterns, Journal of Structural Geology, 8(1986) $563-573$.

\section{Acknowledgements: NIL}

\section{Conflict of interest: NIL}

About The License: (C) 2020 The Authors. This work is licensed under a Creative Commons Attribution 4.0 International License which permits unrestricted use, provided the original author and source are credited. 